\title{
High resolution satellite ortho-images for archaeological research: different methods and experiences in the Near and Middle East
}

\author{
L. Castrianni ${ }^{1}$, G. Di Giacomo ${ }^{2}$, I. Ditaranto ${ }^{1}$, and G. Scardozzi ${ }^{2}$ \\ ${ }^{1}$ University of Salento, Department of Cultural Heritage, Lecce, Italy \\ ${ }^{2}$ CNR-IBAM, Italian National Research Council - Institute for Archaeological and Monumental Heritage, Lecce, Italy
}

Received: 25 January 2010 - Revised: 18 April 2010 - Accepted: 20 April 2010 - Published: 7 May 2010

\begin{abstract}
The paper concerns the very significant contribution of satellite ortho-images to archaeological research. The unavailability of cartography, updated or in adequate scale, is a recurring problem for archaeological research operating in urban and territorial contexts, and in the last years interesting experiences have been carried out with the use of satellite ortho-images; they can provide constant support to field work, both excavations and surveys, and to the management of data in archaeological GIS. As an example of this, the paper shows the results achieved by three research projects carried out by CNR-IBAM in the Near and Middle East, the Hierapolis of Phrygia Survey Project, the Tell Tuqan Survey Project and the Iraq Virtual Museum Project in which base-maps and cartographies satellite ortho-images have been widely used. In these projects, the use of very high resolution satellite images was necessary because large scale and updated cartographies and aerial photos are not available. In the examples shown, satellite ortho-images have different uses, often linked to the possibility or not of an accurate ortho-rectification, with the possibility of the collection of Ground Control Points and with the availability of high resolution DEMs. These images were used to create space-maps for the field work, as well as to realize and update archaeological maps and cartographies finalized to archaeological research. In the cases study presented, WorldView1, QuickBird-2 and Ikonos-2 images, also stereo-pairs, were used.
\end{abstract}

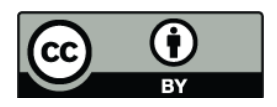

Correspondence to: G. Scardozzi (g.scardozzi@ibam.cnr.it)

\section{Introduction}

In many countries the unavailability of cartography, updated or in adequate scale, is a recurring problem for the archaeological research operating in urban and territorial contexts. In recent years, interesting experiences have been carried out in order to overcome this problem using high resolution satellite ortho-images (Campana and Forte, 2006; Lasaponara and Masini, 2008).

The contribution of these images to archaeological research is very significant, because they can provide constant support for field work, both excavations and surveys, and for the management of data in an archaeological GIS. The processing, analysis and interpretation of traces and anomalies visible in the images and linked to paleo-environmental and archaeological features (from buried to outcropping structures), duly verified on the ground, allow the identification and the spatial characterization of archaeological evidence. Moreover, a correct ortho-rectification of the images provides the creation of space-maps for field work, as well as the realization and the updating of archaeological maps and of cartographies for archaeological research. As a consequence of the possibilities offered by high resolution satellites in order to realize and to updating cartographies, map thematisms can be extracted from ortho-image for the production and upgrading of maps in scales included between 1:10000 and 1:5000. Accordingly, these images can be specifically employed for archaeological research.

During last years the Institute for Archaeological and Monumental Heritage of the Italian National Research Council (CNR-IBAM), in cooperation with the Laboratory of Ancient Topography and Photogrammetry of the Department of Cultural Heritage of the Salento University (Lecce) have

Published by Copernicus Publications on behalf of the European Geosciences Union. 
realized many experiences referring to the use of very high resolution satellite images in archaeological research (Lasaponara and Masini, 2008). Three research projects of CNRIBAM should be mentioned here: the Hierapolis of Phrygia Survey Project, the Tell Tuqan Survey Project, and the Iraq Virtual Museum Project. They concern areas of the Near and Middle East (Turkey, Syria and Iraq) where cartographies are inaccessible, or cannot be updated, and aerial photos are hardly, if at all available. In these study cases, the use of satellite ortho-images was an optimal solution for the creation of topographical maps and space-maps to be used as plans during archaeological field works and in dedicated GIS. In each project, different uses of satellite images (taken by WorldView-1, QuickBird-2 and Ikonos-2) were often linked to the possibility of an accurate ortho-rectification, with the collection of Ground Control Points and with the availability of high resolution DTMs, DEMs and DSMs. The ortho-rectification have varying results according to the reliability of input data such as, for example, orientation parameters of the satellite sensor, the number and distribution of Ground Control Points, the detail of the terrain model available.

With regard to the archaeological researches carried out in Hierapolis and in its surrounding (Denizli, south-Western Turkey), because of the lack of vertical aerial photos and of up-to-date and adequate cartography (the best available topographical maps of the area are on a scale of 1:25000), satellite ortho-images constitute a basic tool for the study of the urban fabric and the direct exploration of the territory. They allow the recording and exact positioning of ancient evidence and archaeological traces. For a limited portion of an area located south-east of the city, between the modern villages of Yeniköy and Küçükdereköy, characterized by a concentration of archaeological evidence dating from the Hellenistic to the Ottoman periods, two topographic maps were performed with the extraction of cartographic and archaeological thematisms from satellite ortho-images.

In the case of the archaeological and topographical researches in Tell Tuqan and in the Maath Region (south of Aleppo, Syria), the creation of an high resolution DTM, the ortho-rectification of satellite images and the analysis and processing of multi-temporal and multi-resolution remote sensing data have allowed the study and the reconstruction of the ancient landscape in the Maath Region, in particular between the proto-historic settlements of Tell Tuqan, Tell Mardikh and Tell Afis.

Finally, satellite ortho-images have provided a large, update and detailed documentation of the modern situation of some ancient cities and settlements of Mesopotamia (from Prehistoric times to the Islamic period) studied and shown in the Virtual Museum of Iraq Project. Multi-temporal high resolution satellite images constitute a fundamental form of documentation and provided plan views of the archaeological areas, where different monuments and excavated areas are together integrated and correctly localized; they allowed to acquire new data about ancient urban layout and landscape, and to upgrade the archaeological plans of the sites. In some case, the recent satellite images were orthorectified (without Ground Control Points and on DEMs based on SRTM data) and the vectorization of all archaeological remains and traces visible in all multi-temporal remote sensing data, allowed the creations of new archaeological maps (ready for the input in a GIS or webGIS) with new data about ancient layout of sites, monuments and roads; in these maps the contour lines were extracted from DEMs.

\section{Satellite ortho-images for archaeological research}

Satellite imagery currently available for civilian use bear characteristics that allow their use for production and updating of cartographies in a scale between 1:10000 and 1:5000; panchromatic images such as those from Ikonos2 and QuickBird-2, and the most recent WorldView-1 and GeoEye-1, have geometric resolutions ranging from 1 and $0.41 \mathrm{~m}$, allowing the creation of base-maps and cartographies in a medium-large scale, replacing or integrating photogrammetric flights, that are in any case irreplaceable for producing or updating large scale cartography ( $\geq 1: 5000)$. Several experiences in this field were made, which resulted particularly important especially in developing Countries or in those areas where cartographies or aerial photogrammetry are inaccessible (Baiocchi et al., 2004; Gianinetto et al., 2004; Jacobsen, 2006). Currently, instead proper photogrammetric applications, based on the use of stereoscopic satellite images, are quite few, also due to this type of images' low availability or high price range; nevertheless, stereo couples acquired from optical sensors can also be used, by means of specific software, for the automatic extraction of DSMs, which, as the DEMs obtained through processing of radar capture, can then be used in orthorectification.

The different uses depend on various factors, including the possibility to generate an accurate ortho-rectification, and Ground Control Points and Check Points (GCPs and CPs) collection and on the availability of high resolution DTMs, DEMs or DSMs. The processing, analysis and interpretation of traces and anomalies linked to buried or partly emerging archaeological and paleo-environmental elements, properly verified on the ground, has enabled the identification and the spatial characterization of archaeological evidence and the reconstruction of the ancient landscape in many contexts. The geometric correction of the images has also enabled the correct positioning and georeferencing of traces, anomalies and ancient evidences, that were subsequently vectorized in the cartographies.

The availability of data in metric or sub-metric resolution has thus allowed to extend scientific interest towards those aspects concerned with cartographic updating and orthoimagery production; the most suitable data for this type of applications are obviously those acquired in panchromatic 
band, since they allow to obtain a better level of detail and definition of the geometric features. Satellite images are always geometrically deformed and consequently it is not possible to measure metrically correct geometric elements directly on them; in order to use them in cartographic applications it is therefore necessary to correct the distortions through ortho-photoprojection. The latter is a digital rectification for which the sensor's internal orientation parameters and a detailed model of the terrain surface are necessary. The use of very high-resolution satellite data for thematic cartography production and updating is today a well-established and rapidly executed procedure. However, in the field of archaeology, due to the heterogeneous nature of the entities that form specialized cartographies and the processes binding map production to the unavoidable on-field verification of acquired data, production time is obviously quite long.

Geometric correction of the images is obtained through the use of mathematical models, today included in most of the widespread data processing software, that can be classified into two large groups: the physical-geometrical models (or parametric) and the generalized models (non-parametric). The first require metadata with the information of the image capture (Rational Polynomial Coefficients - RPCs), that is the data regarding the satellite orbit (ephemerides), platform and sensor orientation, and the data on optical-geometric conditions of the sensor at the time of the acquisition. These models, generally quite reliable, allow the image straightening through the modelling of geometric distortions and by means of a direct connection between image space and terrain space, using a minimum number of variables. However, such models have been supported and partially substituted by general, not parametric models, thus not bound to one particular type of sensor, mostly due to the fact that not all the companies owning the satellites supply metadata regarding the acquisition. Among the non-parametric models, those connected to Rational Polynomial Functions (RPFs) were found to be more reliable, in terms of mean squared errors on points surveyed on the ground relating to the image pixel dimension (Baiocchi et al., 2003; Cheng et al., 2003; Toutin, 2004; Shippert and Zongxiang, 2006). The results of orthorectification of satellite images are quite varying according to the reliability of input data such as, for example, orientation parameters of the satellite-sensor group, the number and distribution of GCPs acquisition, and the detail of the terrain model available.

In those areas where cartographies are inaccessible or not updated, the use of satellite ortho-images represents an optimal solution for the creation of topographical maps and space maps to be used as plans during archaeological field works and in dedicated GIS.

\section{Production of ortho-images, base-maps and topographical maps in the hierapolis of phrygia survey project}

The Hierapolis of Phrygia Survey Project, which began in 2003, is conducted in cooperation with the Italian Archaeological Mission in Hierapolis (Pamukkale, south-west Turkey) and aims at the reconstruction of the urban layout of the city and at the study of its ancient topography and settlement of its territory (D'Andria and Caggia, 2007; Scardozzi, 2007; Castrianni et al., 2008a; D'Andria et al., 2008; Scardozzi 2008a). Thanks to their high spatial, spectral and radiometric resolutions, QuickBird-2 and Ikonos2 images, after processing, have been used in each phase of the research: from the activities on the field to the data analysis and management in the archaeological GIS up to the presentation of the results, giving an important contribution to the archaeological surveys. It is well-known that a numeric cartography on a large scale for the urban area and the necropolises is available, whereas, with regard to the territory that in ancient times was under the control of the city, only raster cartographies are available, scarcely updated and in low detail, therefore of scarce use particularly for field work. So, during the research satellite images were used not only for the identification of traces and anomalies linked to buried or semi-buried archaeological elements. They were also ortho-rectified with the use of Ground Control Points and with DEMs and DSMs processed using different remote sensing data, such as radar (SRTM - Shuttle Radar Topography Mission) and optical (Ikonos-2 and ASTER stereo pairs), in order to create space-maps and extract cartographic elements. These elements were used in order to produce new maps for archaeological purposes and update the existing ones. Moreover, the QuickBird satellite ortho-image of 2005 is the basis of navigation on the urban area and the necropolises in the webGIS of Hierapolis (http://antares.ibam.cnr.it/atlante-hierapolis), along with the archaeological map of the city (Castrianni et al., 2008b).

On the urban area and on the surrounding necropolises a numeric cartography on a large scale $(1: 1000)$ is available, developed in cooperation with the Architecture Faculty of the Polytechnic Institute in Turin; on the contrary, with regard to the large territory that in ancient times was under the control of Hierapolis only raster Turkish maps on a scale 1:25000, drawn in 1970s and updated in 1990s, are available; these maps are poorly detailed, therefore not much useful particularly during archaeological and topographical surveys. Consequently, space-maps of some sectors of the territory have been realized. Their accuracy lies within the cartography products with scale between 1:10,000 and 1:5000, thanks to the ortho-rectification of high resolution satellite images. GCPs and CPs were collected by differential GPS (Sokkia GSR 2700 ISX, equipped with radio modem for real time rectification of the coordinates). Thanks to GCPs and CPs it has been possible to achieve a high degree of accuracy 
and the correction of distortions typical of satellite images. It was also possible to link them to the ground by means of real coordinates. To obtain good ortho-rectifications it was also necessary to take into consideration the position of the satellites during the acquisition (and, consequently, of the sensors mounted on them) in relation to the Earth. These parameters, commonly named Rational Polynomial Coefficients (RPCs), are released in association with each image as metadata. So, we proceeded to the geometric correction of satellite images by various means: the GCPs and CPs, the RPCs, the DTMs obtained through vectorization of contour lines photo projected in the cartography of the General Command of Mapping of Turkey (1:25000 scale). Also we used the DEMs based on SRTM data and the DSMs extracted from a stereo-pair acquired in NIR by Terra satellite with ASTER (Advanced Spaceborne Thermal Emission and Reflectance Radiometer) sensor in 2004. Then, the obtained orthorectified images were used for the production of space maps, which are very important during archaeological surveys and for the placement of archaeological evidence in the GIS of Hierapolis and its surrounding. In these space-maps the contour lines derive from the Turkish carthography.

For small sectors of the territory of Hierapolis, cartographies specifically aimed at the archaeological research were obtained from satellite images. This is a limited area of the territory located south-east of Hierapolis, near the modern villages of Yeniköy and Küçükdereköy, about $2 \mathrm{~km}$ southeast of the ancient town, characterized by a concentration of archaeological evidence dating from the Hellenistic to Ottoman periods. For this area, only a Turkish map 1:25000 in scale updated in the 1990s is available, which is of no help to locate the single archaeological evidence surveyed (Fig. 1). Furthermore, the aerial photos of the area are not available. For this work a stereo pair captured in 2004 by Ikonos-2 (Geo-Ortho Kit Bundle) was used. The satellite panchromatic image with a smaller off-nadir angle has been orthorectified by a DEM and a DSM, elaborated, respectively on SRTM data and an ASTER stereo pair, and by GCPs and CPs collected during field work with a differential GPS system (Fig. 2). The Ikonos-2 stereo pair was processed to create a high resolution Digital Surface Model (Fig. 3). Nevertheless, in this phase we experienced the limit of the algorithms in the shaded areas, in which the 3-D surface model turned out to be very disturbed and not very useful for the reconstruction of the terrain morphology, which requires many interpolations. The equivalent points identified in both stereoscopic images also represented the starting point for their processing to obtain an anaglyph, very useful to highlight the archaeological data from the analysis of micro-relief.

From the Ikonos-2 ortho-image a space map was produced of the entire area of Yeniköy and Küçükdereköy in a 1:10 000 scale; from the same ortho-image many thematisms were also extracted for the creation of two new topographical maps: hydrology, modern topography, field boundaries, archaeological remains and traces, etc. (Fig. 4). The maps obtained (in the tolerance of a 1:10000 scale) are in accordance with the standard themes of cartographic production. Different methods have been compared for the creation of the contour lines: the vectorization of that ones with $10 \mathrm{~m}$ interval of the Turkish cartography in a 1:25000 scale, and the extraction of contour lines with 1 and $5 \mathrm{~m}$ interval from the high resolution DSM extracted from the Ikonos-2 stereo pair, and from DEM and DSM based on SRTM and ASTER data. They come in layers and the different homogeneous elements of the map follow a logical affinity; each represented element in the maps will have its own alphanumeric and colour code according to the information layer to which it belongs (Piccarreta and Ceraudo, 2000). All the archaeological remains detected on the ground during archaeological and topographical surveys have been geo-referenced using a GPS. Moreover, numerous archaeological traces were detected and georeferenced in the new maps also thanks to the analysis of a QuickBird-2 image of the study area taken in 2005 (panchromatic data and pan-sharpened real and false colours images). The data acquired through satellite images processing and analysis, which were confirmed by ground survey, are systematically directed in the Hierapolis GIS, contributing to the enrichment of the archaeological map of the city's territory.

These new topographical maps oriented towards archaeological research, QuickBird-2 ortho-images and space-maps were also used during field work within a system, called Ulixes, developed to provide support to archaeological survey, speeding the positioning and documentation of archaeological presence. The system allows to navigate on cartographies (vector and raster), vertical aerial photos and high resolution satellite images visualized on a Tablet PC linked to a GPS receiver with metric precision. During field work, in the event of an archaeological discovery, it is possible to memorise its position and connect the geographical coordinates as metadata consisting of a record with a detailed description of the type of feature.

\section{High resolution DTM and multi-temporal satellite images in the Tell Tuqan Survey Project}

The Tell Tuqan Survey Project started in 2007 during a collaboration between the CNR-IBAM and the Laboratory of Ancient Topography and Photogrammetry of the University of Salento, within the research activities of the Italian Archaeological Expedition (Ceraudo et al., 2008). Tell Tuqan, is located about $40 \mathrm{~km}$ south-west of Aleppo (Syria) and has an oval plan, with a SSW-NNE elongation, and a 27 ha surface, about $35 \mathrm{~m}$ higher than the surroundings, with its lower and upper town articulation, both bounded by ramparts (Baffi, 2006, 2008). The present shape of the tell is due to the remains of the Middle Bronze Age I-II structures (2000$1600 \mathrm{BC})$, that overlap directly those of the Early Bronze Age IV AB (2500-2000 BC). The field works during the 2007, 2008 and 2009 campaigns are aimed at the production 


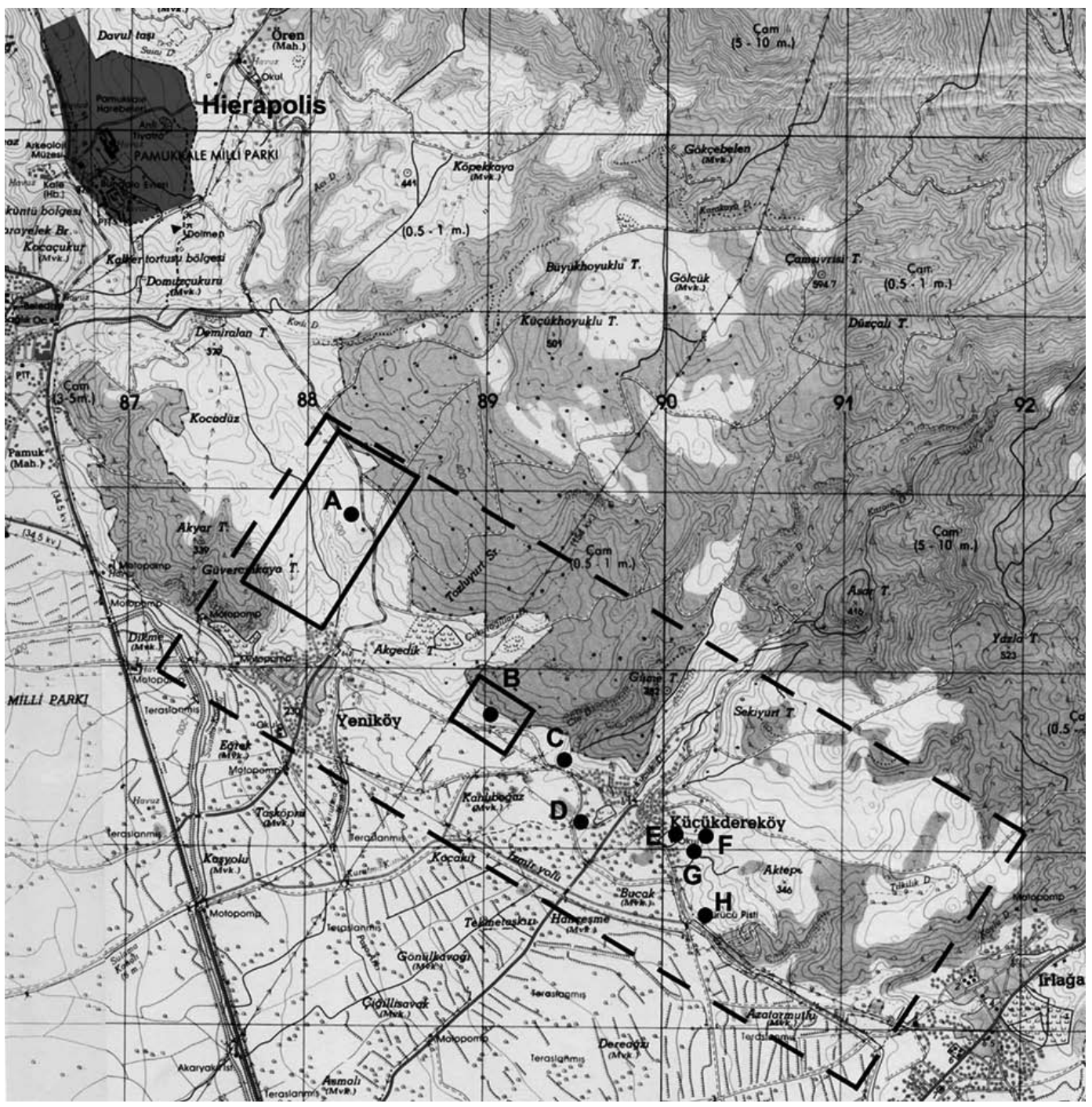

Fig. 1. The area between Yeniköy and Küçükdereköy in the cartography of the Turkish General Command of Mapping (scale 1:25000): the broken line edges the surface of a space-map processed thanks to the ortho-rectification of an Ikonos-2 image, while the unbroken line edges the areas of new topographic maps realized thanks to the vectorization of the Ikonos-2 ortho-image. A: area of an ancient Turkish village north of Yeniköy; B-H: late Hellenistic and Roman necropolises around an ancient village that occupied the area of the modern Küçükdereköy.

of a new topographic map of the tell and mapping of excavation areas, with the use of both a Total Station and a differential GPS. In particular, during the topographical survey of 2007 a new net of elevation points were taken with the Total Station in order to generate a high resolution model of the terrain, useful for the extraction of contour lines for the topographic map (with a $0.5 \mathrm{~m}$ interval). The elevation plan was generated by surveying alignments of elevated points, east-west oriented and parallel to the grid, at about $10 \mathrm{~m}$ intervals on the $x$-axis and $15 \mathrm{~m}$ intervals on the $y$-axis in the upper town. In the lower town, while the interval on the $x$ axis remained of $10 \mathrm{~m}$, it was of about $20 \mathrm{~m}$ on the $y$-axis. In some areas, in order to simplify the surveying operation on the field, the general alignment of the grid was not followed, and clusters of points, rather than alignments, were taken. This high resolution DTM (Fig. 5a-b) is extremely useful for the study of the tell and for a detailed rendering of the morphology of the mound, in way better than the DEM based on SRTM data and the DSM extracted by an ASTER stereo-pair, that are pivotal for the study of large areas.

During the research project, multi-temporal and multiresolution (both high and medium) satellite images were acquired for the study of the tell and the surrounding areas and for the reconstruction of the ancient topography of the Maath Region, where Tell Tuqan is. The same satellite images were used for the study of the territory between the settlement 


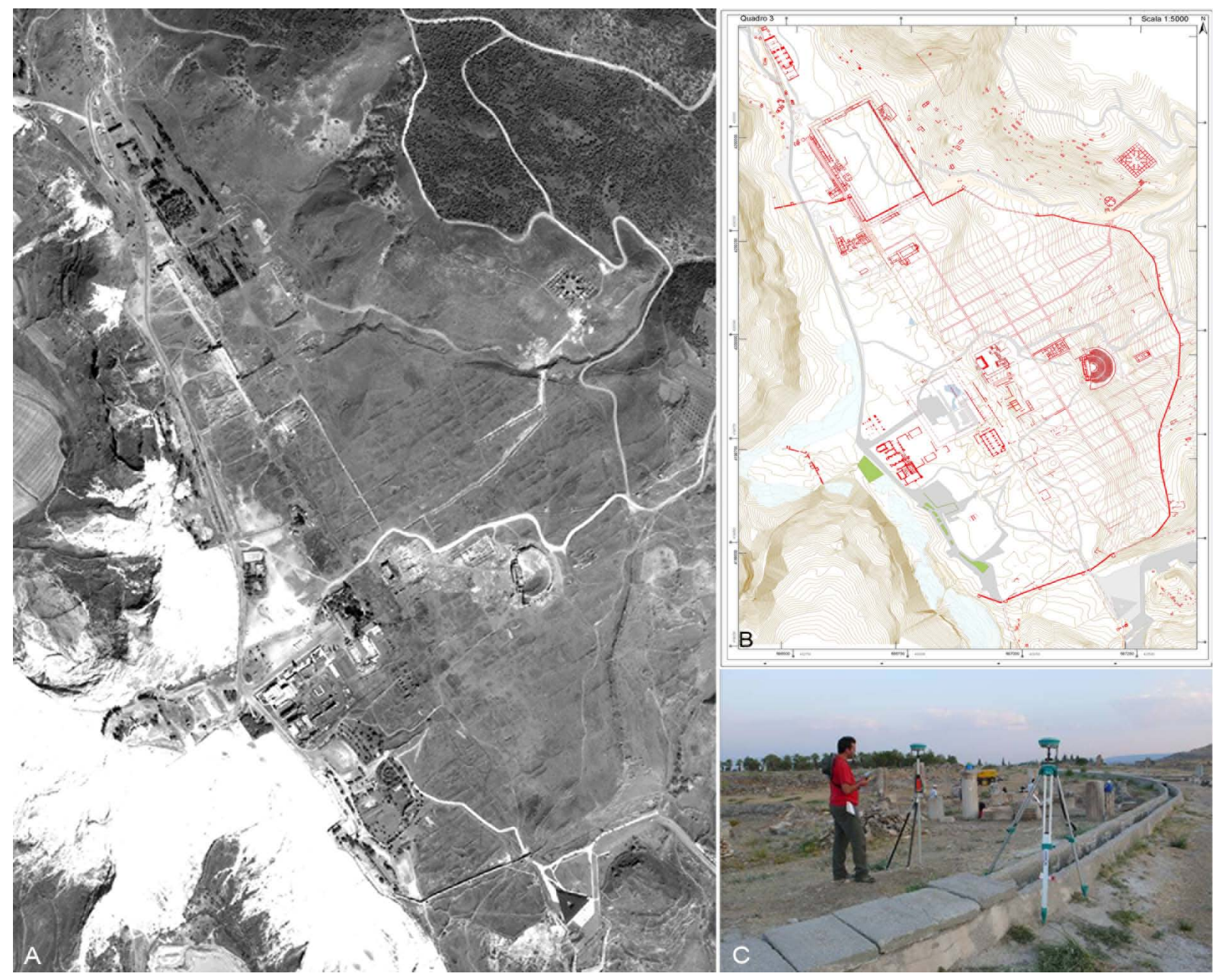

Fig. 2. An example of georeferencing: (A) QuickBird-2 image of the year 2007; (B) archaeological map of the urban area of Hierapolis realized on a scale of 1:5000 in cooperation with the Architecture Faculty of the Polytechnic Institute in Turin (2008); (C) collection of GCPs with a differential GPS.

and the other two important ancient settlements of the region, Tell Mardikh-Ebla and Tell Afis, respectively located $14 \mathrm{~km}$ west/north-west and $16 \mathrm{~km}$ north-west of Tell Tuqan. So, QuickBird-2 standard ortho-ready images of 2004 and 2007 (with a geometric resolution re-sampled to $0.60 \mathrm{~m}$ in panchromatic and $2.40 \mathrm{~m}$ in multispectral mode) were employed and medium resolution pan-sharpened images were taken by Landsat 7 EMT+ between 1999 and 2003 (I-Cubed images in real colours, bands 3-2-1; GeoCover 2000 and OnEarth in real colours - bands 3-2-1 - and in pseudo-colours bands 4-5-2-), and "historical" satellite images, i.e. high resolution space photos taken by US spy satellites in the 1960s and 1970s. In particular, the latest ones images are Corona KH-4A and Corona KH-4B images of 1968 (geometric resolutions of, respectively of about 2.74 and $1.83 \mathrm{~m}$ ), and an Hexagon KH-9 images of 1975 (geometric resolution between 6 and $9 \mathrm{~m}$ ).
The satellite images employed (and their processing) have been georeferenced on the medium resolution DEM and DSM based on SRTM and ASTER data, and on the high resolution DEM generated by the topographical survey of Tell Tuqan, in order to be able to associate the archaeological traces to the ground morphology. Moreover, the QuickBird-2 images were ortho-rectified with the use of the Rational Polynomial Coefficients (RPCs) and the same DEM and DSM based on SRTM and ASTER data, without Ground Control Points (GCPs), in order to create a space-map of the entire area. During field works, GCPs will be measured with a differential GPS, in order to get a better ortho-rectification. For a detailed study of Tell Tuqan, however, during the 2009 campaign, the QuickBird-2 image of the tell taken 29 January 2007 was ortho-rectified with a differential GPS (Sokkia GSR 2700 ISX) on the high resolution DTM processed by the topographical survey with the Total Station. This image has an off-nadir angle of just $2^{\circ}$, so it was taken with the satellite 


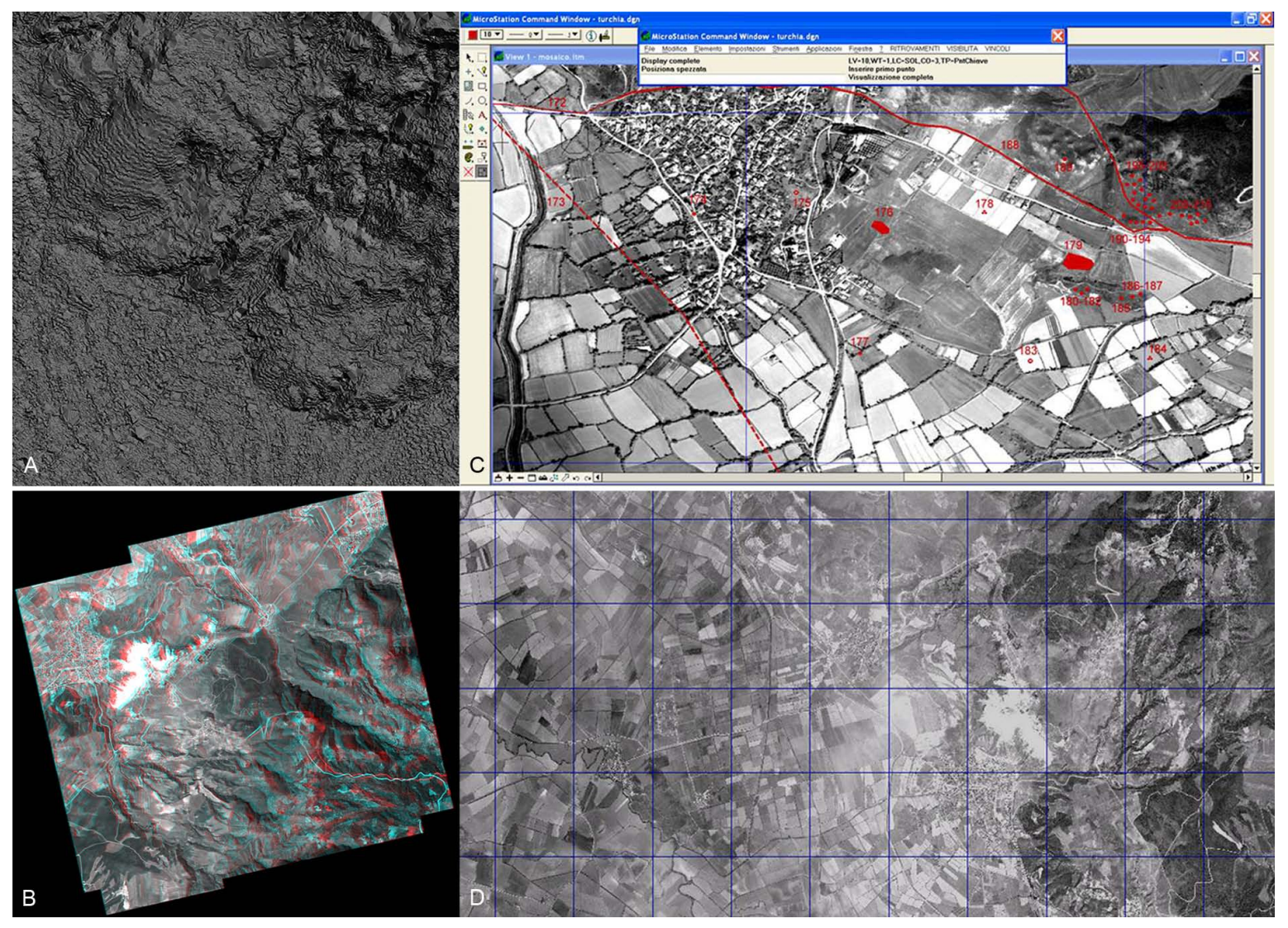

Fig. 3. (A) DSM extracted from the Ikonos-2 stereo pair; (B) anagliph from the Ikonos-2 stereo pair; (C) QuickBird-2 ortho-image in the GIS dedicated to the archaeological survey in the territory of Hierapolis; (D) space-map of a portion of the territory of Hierapolis (grid of $1 \mathrm{~km}^{2}$ ).

sensor almost perfectly vertical over the captured portion of the Earth's surface, with consequent reduction of the geometric distortions of the image (at the time of the acquisition, the geometric resolution was $0.61 \mathrm{~m}$ in panchromatic mode and $2.43 \mathrm{~m}$ in multispectral mode).

The draping of the satellite image on the DTM constitutes a very realistic type of visualization (Fig. $5 \mathrm{c}-\mathrm{d}$ ). It has proven to be extremely effective for the presentation of research results, since it allows the correct three-dimensional placement of the single finds inside their excavation areas; the orthoimage also allows a correct study of the tell and of the surrounding areas. In the QuickBird-2 image of Tell Tuqan, the acropolis and the lower towns can be clearly seen; the ramparts that outline the site are also well visible and they correspond to the defensive system that circled the Middle Bronze town for a perimeter of about $1.6 \mathrm{~km}$. The interruptions of the ramparts corresponding to the three known city gates are well visible, (Fig. 5c-d 1-3: south-west, northeast and south-east), while it can be noticed that the limits of the tell rise considerably as compared to its inner part in the western, northern and eastern sectors; the acropolis fortified perimeter is also evident, interrupted to the north-east by a depression (Fig. 5c-d 4) crossed by a path that leads towards the remains of the south-western gate. The image highlights two interesting dark traces inside the tell: the first possibly corresponds to a road linking the south-western gate to the north-eastern gate (Fig. 5c-d 5). The other, at the northern foot of the acropolis (Fig. 5c-d 6), could correspond to a moat (the trace corresponds to an evident depression in the DTM) at the base of the rampart on which the fortifications were built, defending the higher part of the settlement in this point, separating it from the lower town. Also of a certain interest is the presence, about $110-140 \mathrm{~m}$ south of the site, of a crescent-shaped formation east-west oriented, parallel to the southern side of Tell Tuqan, only partially reached by the modern village (Fig. 5c 7). It is somewhat raised compared to its surroundings, and it is separated from the tell by a slight depression; the current state of research does not allow to establish whether it is a natural formation or the result of archaeological stratification.

The most interesting contribution supplied by multitemporal satellite images, combined with 3-D models of the territory, concerns the reconstruction of the environment in which Tell Tuqan rose. If the recent images (Fig. 6a) 


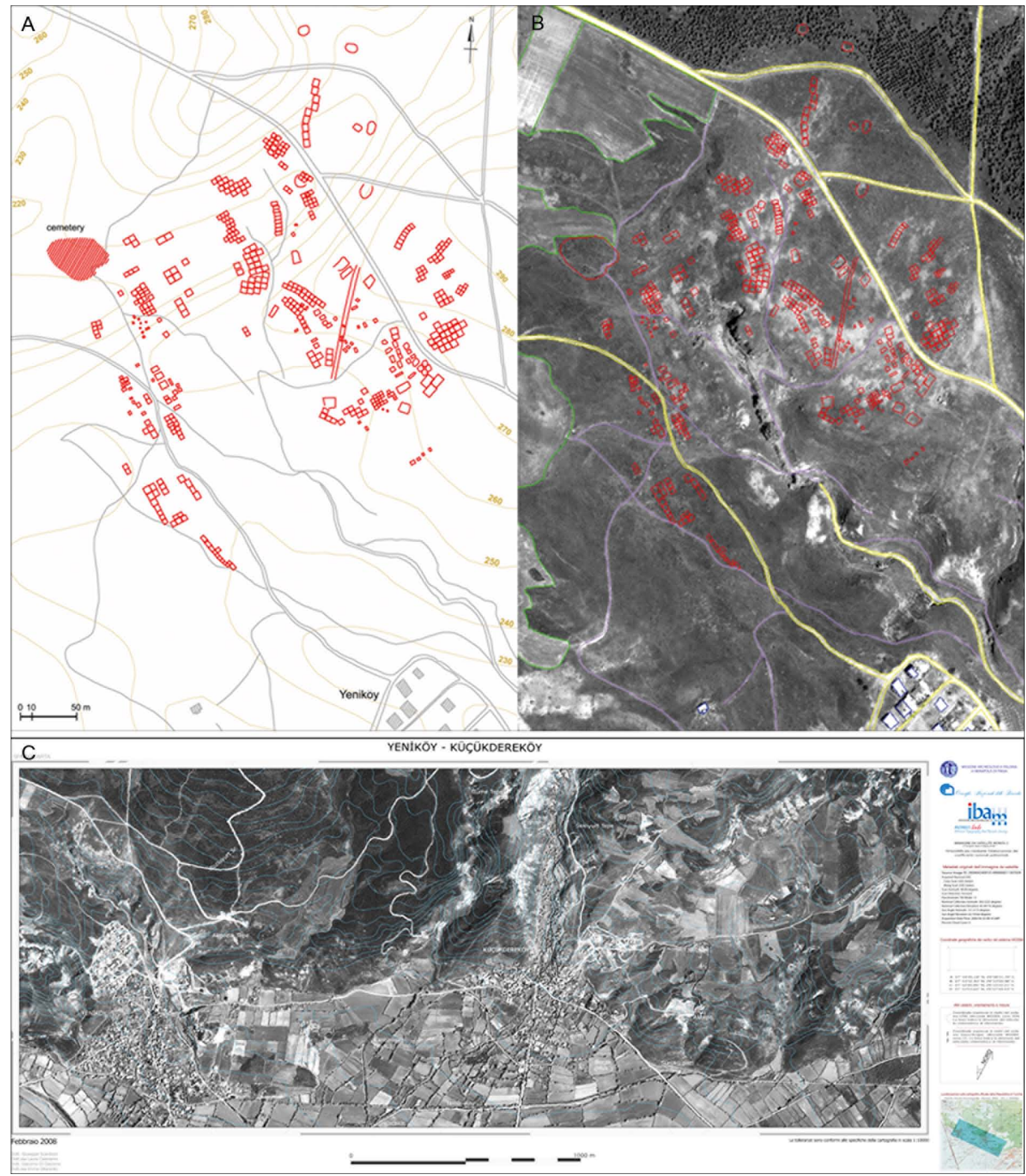

Fig. 4. (A)-(B) An example of cartography specifically finalized to archaeological research obtained from satellite images: vectorization of archaeological evidences of a Turkish ancient village and modern topography from satellite ortho-images. (C) Space-map of the YeniköyKüçükdereköy area: the contour lines are vectorized from the Turkish Cartography of the General Command of Mapping.

document quite clearly the humid area extending just east of the tell, made of both residual moisture in the ground and water on the surface, this situation had been much more clear in the 1968 images. In particular, the Corona KH-4B photo taken in November (Fig. 6b) shows an extensive trace of residual humidity corresponding to the depression (Maath) into which flowed the Nahr el-Quweyq, while in the Corona $\mathrm{KH}-4 \mathrm{~A}$ photo of March (Fig. 6c) the same area is partially filled with water, thus showing the lake that occupied the area in antiquity. In the latter image, the waters almost reach the site. The residual moisture traces also present on the western side of the mound, which are also visible in the Corona 


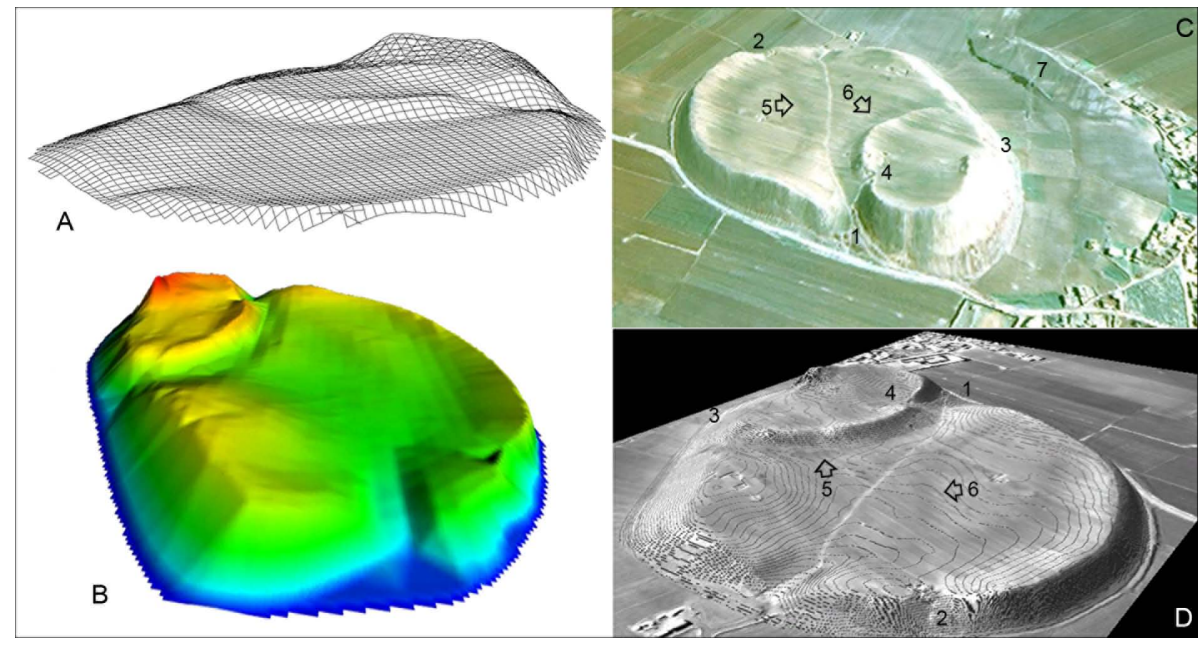

Fig. 5. Tell Tuqan. Mesh (1) and three dimensional model with exalted elevation (2), extracted from the elevation points collected during the field works of 2007-2009; draping of the QuickBird-2 satellite image (29 January 2007) on the DTM for a realistic visualization, in real colours (3) and panchromatic mode with contour lines (4).

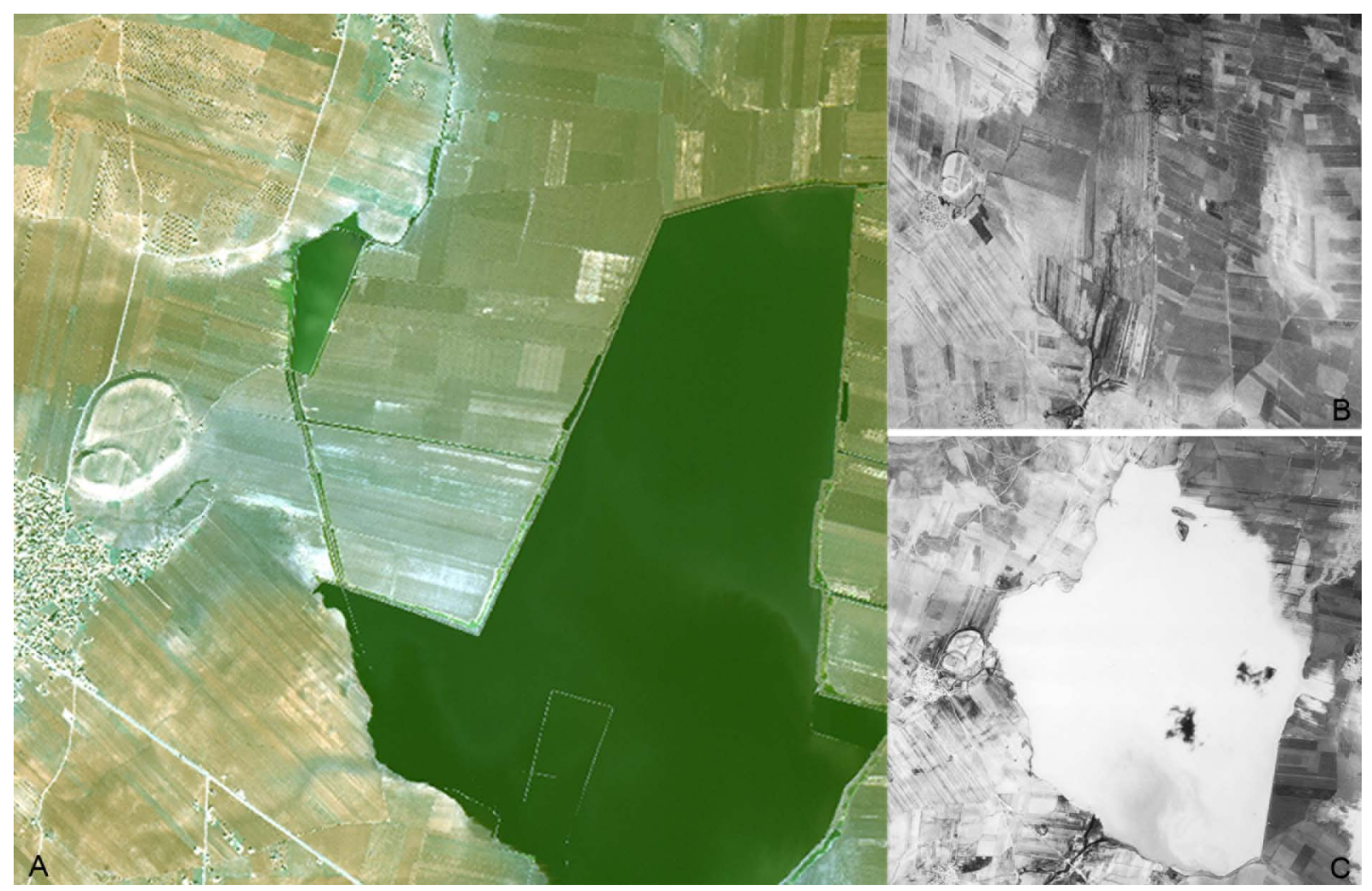

Fig. 6. The humid area extending just east of Tell Tuqan in a QuickBird-2 image of 2007 (A) compared with two 1968 images: a Corona KH-4B photo of 20 November (B), where an extensive trace of residual humidity is visible, and a Corona KH-4A photo of 21 March (C), which shows the lake that occupied the area near the tell.

KH-4A photo of November, seem to suggest that in particularly rainy periods water almost entirely surrounded Tell Tuqan. It is clear how the settlement rose on the western side of a wide humid area, where the grounds were drier, albeit probably crossed by wadis, whose paleo-channels are visible in the Corona KH-4A photo of March 1968 (Fig. 7), for the most part south-west/north-east or west/east oriented, in the direction of the depression. The same image also shows 

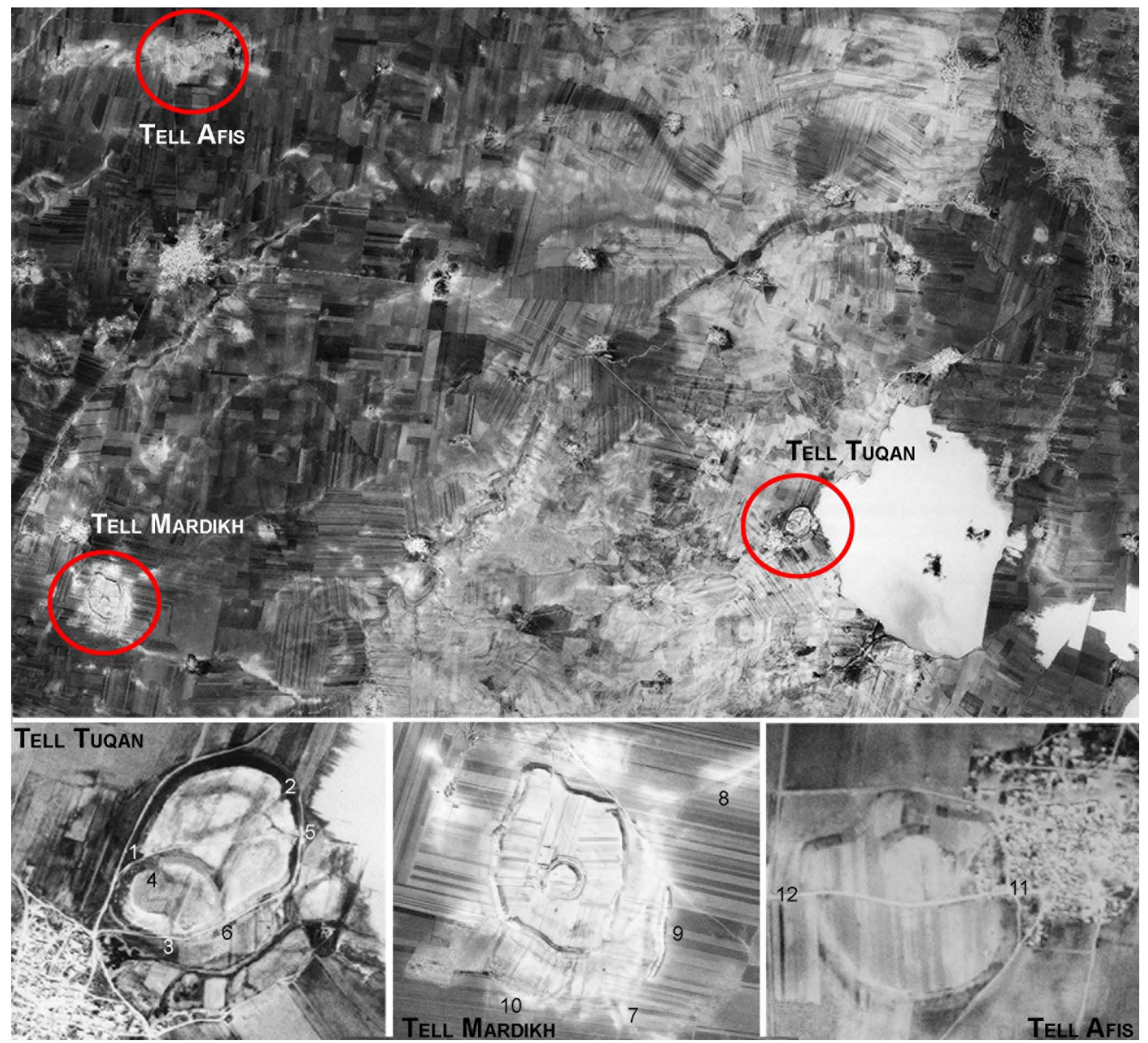

Fig. 7. A Corona KH-4A (21 March 1968) photo shows interesting data about the ancient viability, paleo-river beds and settlements of the territory between Tell Tuqan, Tell Mardikh and Tell Afis.

interesting details of the tell, ten years before the beginning of the Italian excavations, when its surface was still used to grow crops: in particular, the gaps in the tell's margins corresponding to the three gates are clearly visible (Fig. 7, 13 ), the gap that goes from the acropolis towards the southwestern gate (Fig. 7, 4), and other two, one south of the north-eastern gate (Fig. 7, 5) and another south-east, where the acropolis meets the lower town (Fig. 7, 6). Furthermore, the south-western and north-eastern gates are joined by a path, and the traces of a possible moat are visible at the northern foot of the acropolis. The research on the territory west of Tell Tuqan, still in progress, also highlights interesting data. The roads that from the tell run towards west/south-west, in the direction of Tell Mardikh-Ebla, and north-west, towards Tell Afis, are also visible in the satellite images, in particular in the Corona 1968 photos (Fig. 7). Their routes are par- tially followed by modern roads. Better than the recent ones, the images of 1968 also show, outside the evident ramparts that surround the lower town of Tell Mardikh, traces of several stretches of ancient roads that stretched outwards from Ebla from the south-eastern and north-eastern gates (Fig. 7, $7-8$ ). Moreover, the presence of a $520 \mathrm{~m}$ long stretch of earth rampart running north/south, parallel to the eastern limit of the lower town and at a distance of about $220 \mathrm{~m}$ from it can also be noticed (Fig. 7, 9), and another stretch of rampart, east/west oriented, about $75 \mathrm{~m}$ long and currently flattened, is visible about $200 \mathrm{~m}$ beyond the southern limit of the lower town (Fig. 7, 10). Finally, regarding Tell Afis, the Corona photos of 1968 show the site plan almost free of the modern buildings that today occupy its eastern and north-eastern limits. The perimeter of the mound is well defined, also on the south-western side, where today it appears less marked. 


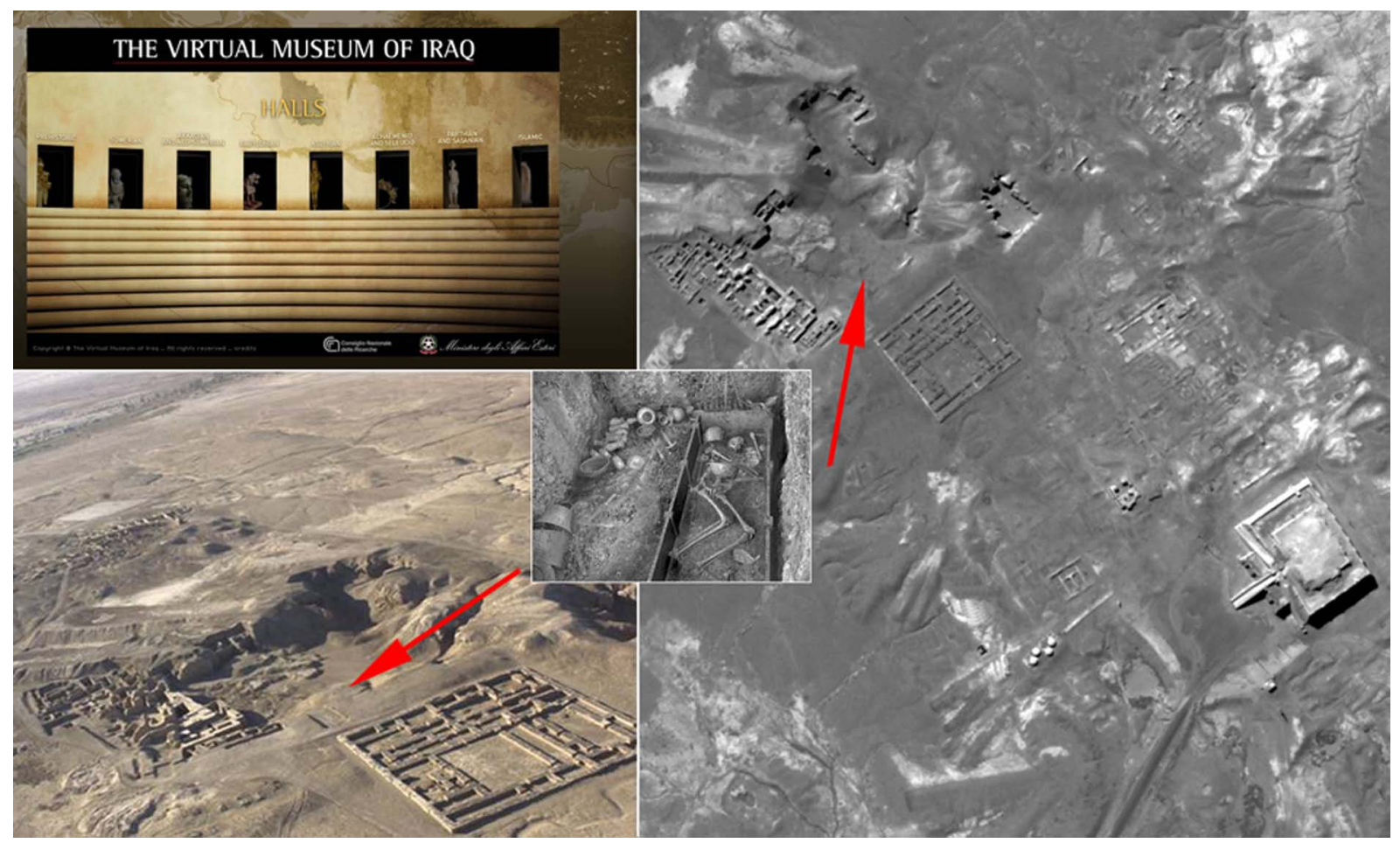

Fig. 8. The contextualization of the tomb of Meskalamdug in the Royal Cemetery of Ur (Sumerian Hall): the entry page to the eight halls of the Iraq Virtual Museum web site, an aerial photo and a satellite Quickbird-2 image of 2004.

The rampart that enclosed the settlement, about $1.8 \mathrm{~km}$ long, appears slightly raised as compared to the lower town (about $24 \mathrm{ha}$ ), and it corresponds to the Iron Age II-III (half of IX end of VII cent. BC) fortifications, when this part of the site was densely inhabited. The acropolis is also clearly visibile, decentred northwards, and surrounded by a large defensive wall already in Middle Bronze Age I-II (1850-1700 BC). Possibly a gate was located on the eastern side and another one on the western side, which today are crossed by a road that cuts the tell (Fig. 7, 11-12).

\section{Production of new archaeological maps of ancient sites in the Iraq virtual museum project}

In the Iraq Virtual Museum Project, promoted in 2006 by the Italian Ministry of Foreign Affairs, the goal is the construction of a Virtual Museum of the ancient civilizations that flourished in the Iraqi territory: a rich website, which is free of charge for the general public, based on the archaeological collection of the National Museum of Baghdad. The activities of CNR-IBAM are focused on the realization of a virtual tour of the most important archaeological Iraqi sites, and on the contextualization of the finds stored in the Baghdad Museum, linking them to their sites of provenance (Gabellone and Scardozzi, 2006; Gabellone and Scardozzi, 2007; Cultraro et al., 2007; Cultraro et al., 2009). For each chronological "Room" of the Virtual Museum (from Prehistoric times to Islamic period), in the section "Archaeological Sites" two or three more representative archaeological sites have been chosen: Ur, Uruk (Warka), Tell Es-Sawwan, Tell Asmar, Ashur, Kalhu (Nimrud), Dur-Sharrukin (Khorsabad), Nineveh, Babylon, Sippar, Kish, Seleucia on the Tigris, Ctesiphon, Hatra, Baghdad, Samarra and Ukhaydir. They were documented by cataloguing the most significant monuments, in terms of historical and topographical development, in order to provide the "visitor" to the Virtual Museum with a complete picture of the characteristics of the contexts where the artefacts were found. In a few cases, some monuments or cities have been also reconstructed by means of 3-D imagebased modelling and rendering (photo-modelling and digital photogrammetry). The process of contextualization allows the Virtual Museum visitors to view the original territorial contexts of the finds, i.e. the archaeological sites from which the materials came from (Fig. 8). For the virtual visit to the place of provenance in its current situation, considerable problems arise for contexts that are not easily accessible, and where abundant, adequate and recent photographic or graphic documentation is not available. In the case of many ancient Iraqi cities and settlements, generally only few terrestrial images and some oblique aerial photographs of limited parts of the archaeological areas are available for these, together with some documents (graphic and photographic) of the excavations. An important contribution to the 


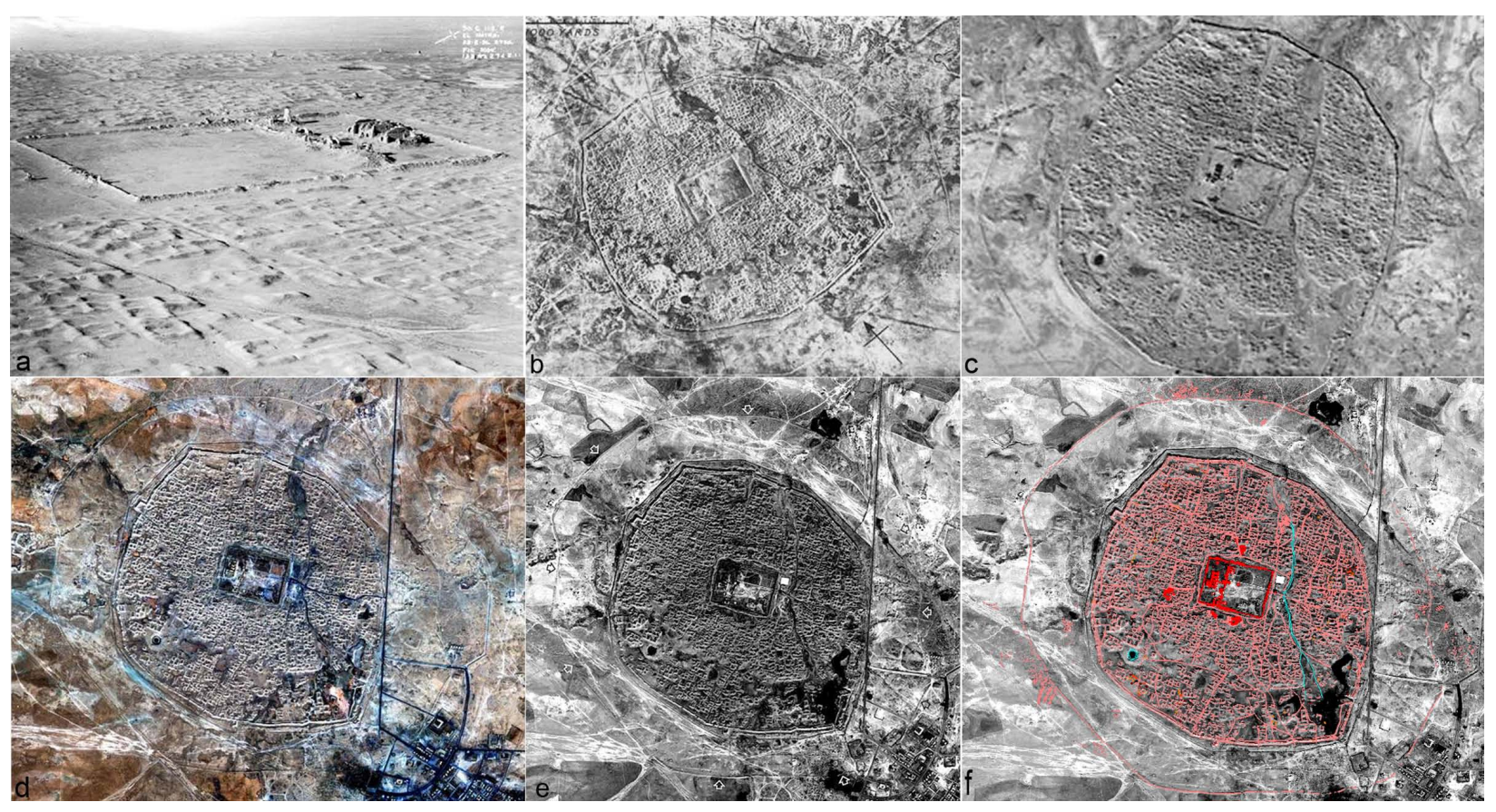

Fig. 9. Hatra, example of multi-temporal aerial and satellite documentation of: (a) oblique RAF aerial photo (1930); (b) vertical RAF aerial photo (1936-39); (c) Corona KH-4B satellite photo (1967); (d) Ikonos-2 image (2002); (e) QuickBird-2 image (2006); (f) Ortho-rectified QuickBird-2 image of 2006 with vectorization of the archaeological evidence (in pink) and georeferenced plans of monuments (in red).

resolution of this problem was provided by high resolution multi-temporal satellite images, taken by commercial satellites (Ikonos-2, QuickBird-2, WorldView-1) between 2001 and 2008 in a very high resolution, between 0.50 and $1 \mathrm{~m}$ in panchromatic mode and 2.40 and $4 \mathrm{~m}$ in multispectral. As a consequence, in the chronological sections of the Virtual Museum the contextualization was obtained with different solutions dedicated to different end-users: virtual reconstructions of archaeological sites or monumental contexts, images (maps, plans, photos, air-photos, satellite images) in the section "Archaeological Sites" of the website, that offer a synthetic image of the characteristics of the ancient cities, settlements and contexts where the artifacts were found.

Multi-temporal satellite images (Fig. 9) constitute a large documentation very useful for the presentation of some of the most important ancient cities and archaeological settlements of Mesopotamia, and for monitoring their transformations in recent years, as well as their state of preservation or possible damage (Scardozzi, 2008b). When it was possible, images taken before and after the second Gulf War were used for each archaeological site. For a documentation of the situation before the first Gulf War and chronologically closer to the times of many archaeological excavations, for all the sites studied some space photos of 1960s and 1970s taken from United States reconnaissance satellites (Corona KH-4A and KH-4B, Gambit KH-7 and Hexagon KH-9, with a geometric resolution between 0.60 and $9 \mathrm{~m}$ ) were acquired, in some cases within aerial photos taken in 1920s, 1930s and 1940s by Royal Air Force pilots. These images are very important, because they allowed to collect a lot of data on territories that usually appear developed and have been partially modified and altered. So they constituted a precious documentation of archaeological areas before recent transformations and in some cases showed ancient features today not visible or destroyed (Scardozzi, 2008c).

These multi-temporal remote sensing data are a fundamental documentation in order to correctly narrate so to speak the sites under study. These images make it possible to observe and document the archaeological areas as they are today, both as a substitute for a real visit (which is currently impossible), and in view of a future real visit. The detailed examination of all these images also constitutes an important opportunity to acquire new data on the topographical layout of the sites, their principal monuments and paleo-environmental contexts, which are instrumental for the reconstruction of the historic landscape in which the settlements were situated. Their high geometric resolution makes them similar, in terms of definition, to vertical aerial photographs on a middle scale, which are hardly available for the studied areas. Consequently, satellite images provide a detailed view from above of the current state of the archaeological sites and their layouts, offer the possibility of noticing even quite small details, allow us to identify elements that are not easily perceptible on the ground (like ancient roads and canals now 


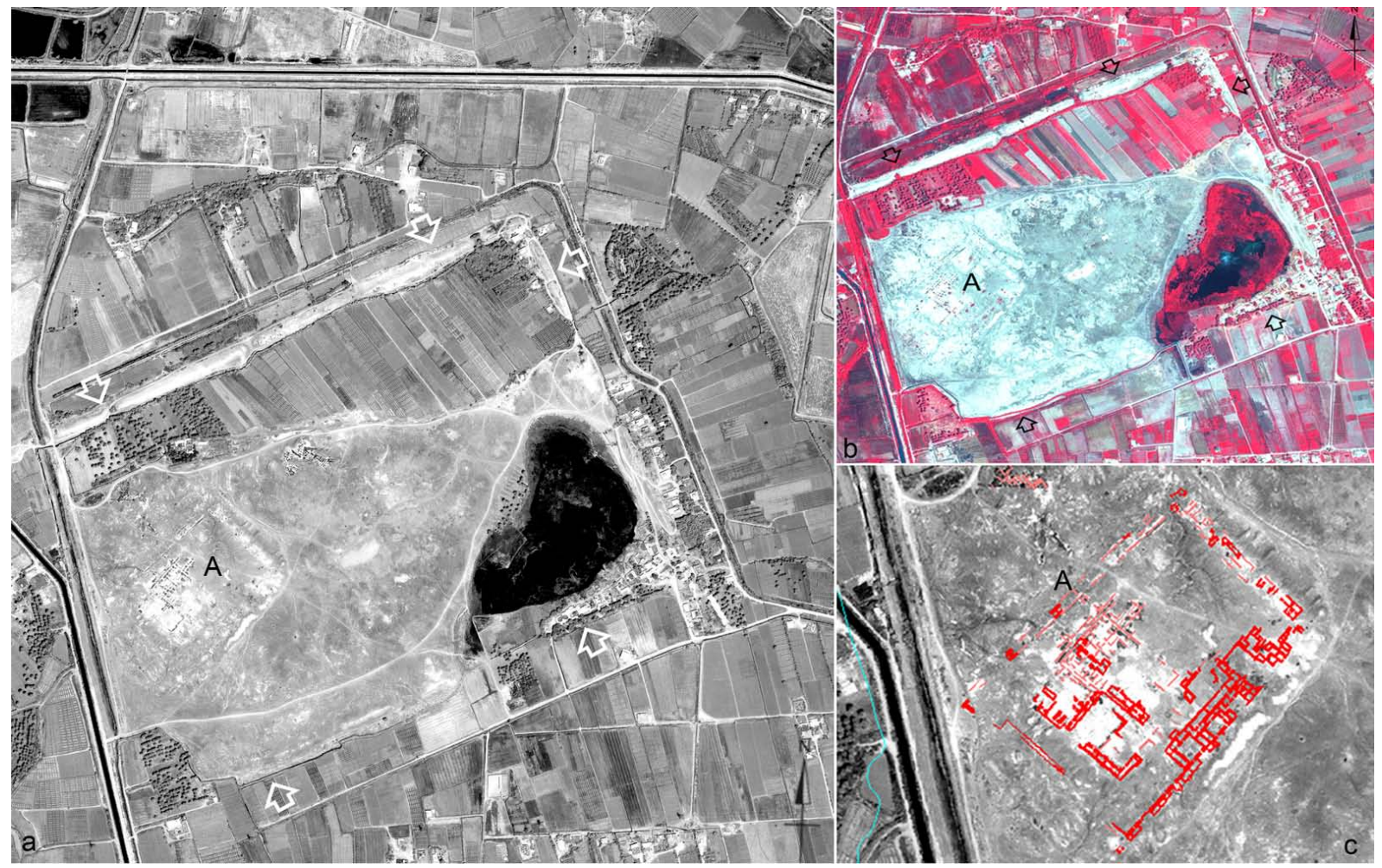

Fig. 10. Sippar: Ikonos-2 panchromatic image of 2002 (a) and QuikBird-2 pan-sharpened in false colors infra-red image of 2007 (b) with the remains of the E-babbar Temple (A) and the traces of the city walls; (c) ortho-rectified QuickBird-2 image with vectorization of the archaeological traces and georeferencing of monuments plans.

buried, paleo-river beds, etc.) and to recognize the traces of ancient structures that are still buried or are now interred again since their original excavation. These images provide a complete multi-temporal documentation of the archaeological areas available, where different monuments are integrated and correctly localized.

During the activities of the Iraq Virtual Museum Project, the study and the analysis of panchromatic images represented an opportunity to acquire new data on the ancient topography of some of the archaeological sites examined. This documentation was very important specifically for contexts that have been studied many years ago or that are characterized by a history of the research centered mainly on individual complexes, monuments or wealth of finds and has not interested the general layout of settlement. In some cases, the processing of multispectral images of Ikonos-2 and QuickBird-2, and the data fusion between panchromatic images and multispectral elaborations also make it possible to better identify and highlight archaeological and paleoenvironmental traces and anomalies. However it is important to specify that in the analysis of remote sensing data, verification on the ground of presences, traces and anomalies, in order to clarify their real pertinence to archaeological elements, their interpretation and, if possible, also their dating, avoiding misunderstandings and mistakes. But in the study cases of the Project, the ground control with a survey of the sites was impossible, so in most cases we could just formulate some hypotheses comparing them to the published studies.

In the case of some ancient sites studied, recent highresolution satellite images were ortho-rectified without Ground Control Points and on DEMs based on SRTM data, and used for the creation or the update of the (generally very old) archaeological maps, on which plans of excavated structures, recent discoveries, archaeological traces and paleoenvironmental elements were geo-referenced. So it was possible to upgrade the archaeological plans of the sites and create a vector documentation utilized for 3-D reconstructions of monuments and ancient cities (Fig. 10). Thus, the vectorization of all archaeological remains and traces visible in all multi-temporal remote sensing data allowed the creation of new archaeological maps (ready for input in a GIS or webGIS) with new data on ancient layout of sites, monuments and roads; in these maps the contour lines were extracted from DEMs. These new maps will be collected in an "Atlas" (a hardcover volume available for scientists and scholars, still in progress) of the more important Iraqi archaeological sites, including all the documentation analyzed for the project: processed satellite images and photos, reports of the data derived from the analysis of the images, virtual 
reconstructions, schedules of the ancient sites where historical and topographical development of the settlement layout and of the most significant monuments are analyzed.

Acknowledgements. The authors sincerely thank Francesco D'Andria, Director of the Italian Archaeological Expedition of Hierapolis in Phrygia and of CNR-IBAM, Francesca Baffi, Director of the Italian Archaeological Expedition of Tell Tuqan in Syria and Dott. Massimo Cultraro, Scientific Coordinator of the Iraq Virtual Museum Project.

Sections 1 and 4 are written by Giuseppe Scardozzi, Sect. 2 by Giacomo Di Giacomo, Sect. 3 by Laura Castrianni and Sect. 5 by Imma Ditaranto.

Edited by: L. Eppelbaum, N. Masini, and F. Soldovieri Reviewed by: two anonymous referees

\section{References}

Baffi, F. (Ed.): Tell Tuqan, Ricerche archeologiche italiane nella regione del Maath (Siria), Galatina 2006.

Baffi, F. (Ed.): Tell Tuqan, Excavations 2006-2007, Galatina 2008.

Baiocchi, V., Crespi, M., De Vendictis, L., and Lorenzon, F.: Impiego cartografico di immagini satellitari ad alta risoluzione. Le problematiche metriche: dati primari, metodologie, sperimentazioni, in La Cartografia per il controllo e la gestione del territorio. Atti del Convegno (Lamezia Terme, 12-13 giugno 2003), 2003.

Baiocchi, V., Crespi, M., De Vendictis, L., and Giannone, F.: Ortorettificazione Di immagini satellitari ad alta risoluzione per scopi cartografici: Metodologie ed implementazione di un nuovo software, bollettino sifet, 1, 11-33, 2004.

Campana, S. and Forte, M. (Eds.): From Space to Place. Proc. of the 2nd International Conference on Remote Sensing in Archaeology (CNR, Rome, 4-7 December 2006), Archaeopress BAR International Series 1568, Oxford, 2006.

Castrianni, L., Di Giacomo, G., Ditaranto, I., and Scardozzi, G.: Integrated technologies and methodologies for the reconstruction of the ancient topography of Hierapolis in Phrygia and its territory (Turkey), in Proc. of the International Congress "Cultural Heritage and New Technologies", Workshop 13 - Archäologie und Computer (Vienna City Hall, 3-5 November 2008), $2008 \mathrm{a}$.

Castrianni, L., Di Giacomo, G., Ditaranto, I., and Scardozzi, G.: An Online Archaeological Atlas: the webGIS for the Monuments of Hierapolis in Phrygia, Archaeological Computing Newsletter, $69,1-8,2008 b$.

Ceraudo, G., Di Giacomo, G., Scardozzi, G.: Tell Tuqan. Topographic mapping, DEM and high resolution satellite images, in: Tell Tuqan, Excavations 2006-2007, edited by: Baffi, F., Galatina, 193-210, 2008.

Cheng, P., Toutin, P., and Zhang, Y.: QuickBird - Geometric correction, data fusion, and automatic DEM extraction, in 24th Asian Conference on Remote Sensing, 2003.

Cultraro, M., Gabellone, F., and Scardozzi, G.: Integrated methodologies and technologies for the reconstructive study of DurSharrukin (Iraq), Proc. CIPA 2007, I, 253-258, 2007.

Cultraro, M., Gabellone, F., and Scardozzi, G.: The virtual musealization of archaeological sites: between documentation and communication, in Proceeding of the Workshop on 3-D Virtual Reconstruction and Visualization of Complex Architectures (Trento, 25-28 February 2009), 2009.

D’Andria, F., Caggia, M.P. (Eds.): Hierapolis di Frigia, I. Le attività delle campagne di scavo e restauro 2000-2003, Ege Yayınları, Istanbul, 2007.

D’Andria, F., Scardozzi, G., Spanò, A. (Eds.): Atlante di Hierapolis di Frigia, Ege Yayı nlar $\iota$, Istanbul, 2008.

Gabellone, F. and Scardozzi, G.: Integrated technologies for the reconstructive study of Mesopotamian cultural heritage: the cases of Ur, Uruk and Nimrud, in Proc. of the International Congress "Cultural Heritage and New Technologies", Workshop 11 Archäologie und Computer (Vienna City Hall, 18-20 October 2006), 2006.

Gabellone, F. and Scardozzi, G.: From the object to the territory: image-based technologies and remote sensing for the reconstruction of ancient contexts", in: Virtual Museums and Archaeology, edited by: Moscati, P., Archeologia e Calcolatori, Suppl. 1, 123142, 2007.

Gianinetto, M., Giussani, A., Lechi, G. M., and Scaioni, M.: Fast mapping from high resolution satellite images: a sustainable approach to provide maps for developing countries", in XXth ISPRS Congress (Istanbul, 12-23 July 2004), 2004.

Jacobsen, K.: Comparison of photogrammetric applications based on narrow angle line scanners with traditional photogrammetric methods, in: The future of remote sensing, edited by: Everaerts, J., 2nd International Workshop (Antwerp, 17-18 October 2006), 2006.

Lasaponara, R. and Masini, N. (Eds.): Remote sensing for Archaeology and Cultural Heritage Management. Proc. of the 1st International Workshop (Rome, 30 September-4 October 2008), Aracne Editrice, Rome, 2008.

Piccarreta, F. and Ceraudo, G.: Manuale di aerofotografia archeologica. Metodologia, tecniche e applicazioni, Edipuglia, Bari, 2000.

Scardozzi, G.: Remote sensing and archaeological survey in the Hierapolis of Phrygia territory, Turkey, in Proc. SPIE 6749-04/112, 2007.

Scardozzi, G.: Hierapolis of Phrygia Project: integration of archaeological survey and remote sensing data, in: Lasaponara and Masini 2008, 425-428, 2008a.

Scardozzi, G.: Multitemporal remote sensing data for the knowledge and the monitoring of the Iraqi archaeological sites, in Lasaponara and Masini 2008, 343-346, 2008b.

Scardozzi, G.: Old high resolution satellite images for landscape archaeology: case studies from Turkey and Iraq, in Proc. SPIE 7110-03/1-14, 2008c.

Shippert, P. and Zongxiang, P. Y.: Extracting DEM's from stereo imagery, GEOconnexion International Magazine, 26-27, February, 2006.

Toutin, T.: Geometric processing of remote sensing images: models, algorithms and methods, Int. J. Remote Sens., 25(10), 18931924, 2004. 